\title{
Effects of Good Pain Management (GPM) ward program on patterns of care and pain control in patients with cancer pain in Taiwan
}

\author{
Wei-Chih Su ${ }^{1} \cdot$ Chieh-Han Chuang ${ }^{2,3}$ • Fang-Ming Chen ${ }^{3,4,5} \cdot$ Hsiang-Lin Tsai ${ }^{1,4} \cdot$ Ching-Wen Huang ${ }^{1,4}$. \\ Tsung-Kun Chang ${ }^{1}$ • Ming-Feng Hou ${ }^{3,5,6}$. Jaw-Yuan Wang ${ }^{1,5,6,7,8,9,10}$
}

Received: 3 April 2020 / Accepted: 24 July 2020 / Published online: 15 August 2020

(C) The Author(s) 2020

\begin{abstract}
Background The undertreatment of cancer pain is a global issue although many international guidelines and various studies bloom to explore the approaches in pain management. However, there is no standard care for cancer pain in routine practices. To set up a standardized procedure for improving cancer pain management in Taiwan, the Good Pain Management (GPM) program is explored to provide treatments following the US National Cancer Care Network (NCCN) Adult Cancer Pain Guideline.

Method Patients diagnosed with moderate-to-severe cancer pain were eligible and randomized into the GPM or control arm and observed the first $48 \mathrm{~h}$ to evaluate the effects of pain management between 2 arms. Pain control, adequacy of treatments, patient satisfaction, and quality of life (QoL) of eligible patients were analyzed. Ad hoc analyses based on the pain medication category were also conducted.

Result Fifty-one patients were enrolled, with 26 and 25 assigned to the GPM and control arms, respectively. Significant differences among the GPM and control arms were found including a greater decrease in the mean numerical rating scale (NRS) score in the GPM arm (-4.6 vs. -2.8$)$, a lower proportion of moderate-to-severe pain in the GPM arm $(23.2 \%$ vs. $39.8 \%$ ), and a higher pain management index (PMI) score in the GPM arm (0.64 points vs. 0.33 points) (all $p<0.05)$. Ad hoc analyses revealed that the patient subgroups using strong opioids showed better patient satisfaction in GPM arm when compared with the same subgroup in the control arm.

Conclusion In summary, our study demonstrated that the implementation of a standardized pain assessment and management approach (GPM ward program) showed significant improvements on pain relief, decreased the portion of moderate-to-severe cancer pain, and increased patient satisfaction in the $1 \mathrm{st} 48 \mathrm{~h}$ after admission. The implementation of the GPM approach in the cancer ward may provide sooner and better improvement of cancer pain management for patients who suffered moderate-tosevere cancer pain.
\end{abstract}

Trial registration ClinicalTrials.gov (Identifier: NCT03155516)

Keywords Good pain management · Pain control · Adequacy of pain treatment $\cdot$ Cancer pain

Wei-Chih Su and Chieh-Han Chuang contributed equally to this work.

Jaw-Yuan Wang

cy614112@ms14.hinet.net; jawyuanwang@gmail.com

1 Division of Colorectal Surgery, Department of Surgery, Kaohsiung Medical University Hospital, Kaohsiung Medical University, No. 100 Tzyou 1st Road, Kaohsiung 807, Taiwan

2 Department of Surgery and ICU, Kaohsiung Municipal Siaogang Hospital, Kaohsiung, Taiwan

3 Division of Breast Surgery, Department of Surgery, Kaohsiung Medical University Hospital, Kaohsiung Medical University, Kaohsiung, Taiwan

4 Department of Surgery, Kaohsiung Municipal Ta-Tung Hospital, Kaohsiung, Taiwan
5 Department of Surgery, Faculty of Medicine, College of Medicine, Kaohsiung Medical University, Kaohsiung, Taiwan

6 Graduate Institute of Clinical Medicine, College of Medicine, Kaohsiung Medical University, Kaohsiung, Taiwan

7 Graduate Institute of Medicine, College of Medicine, Kaohsiung Medical University, Kaohsiung, Taiwan

8 Center for Cancer Research, Kaohsiung Medical University, Kaohsiung, Taiwan

9 Cohort Research Center, Kaohsiung Medical University, Kaohsiung, Taiwan

10 Master Program for Clinical Pharmacogenomics and Pharmacoproteomics, School of Pharmacy, Taipei Medical University, Taipei, Taiwan 


\section{Introduction}

Pain is one of the most common symptoms occurring in 53\% of cancer patients in all stages of the disease, and over $70 \%$ of patients in advanced stages experience uncontrolled pain of moderate-to-severe intensity worldwide [1-3]. Also, unrelieved pain is highly associated with affecting emotion, activity, and the quality of life for patients [4-6]. Although there are international guidelines for pain management [7-10], the undertreatment of cancer pain is still a widespread issue in Asia, Europe, and North America for $59.1 \%, 40.3 \%$, and $39.1 \%$ of cancer patients, respectively [2]. Okuyama et al. [11] and Vuong et al. [12] focused on the evaluation of adequacy for pain management using the pain management index (PMI) [13] and results showed that pain management needed to be improved based on a high proportion of patients with

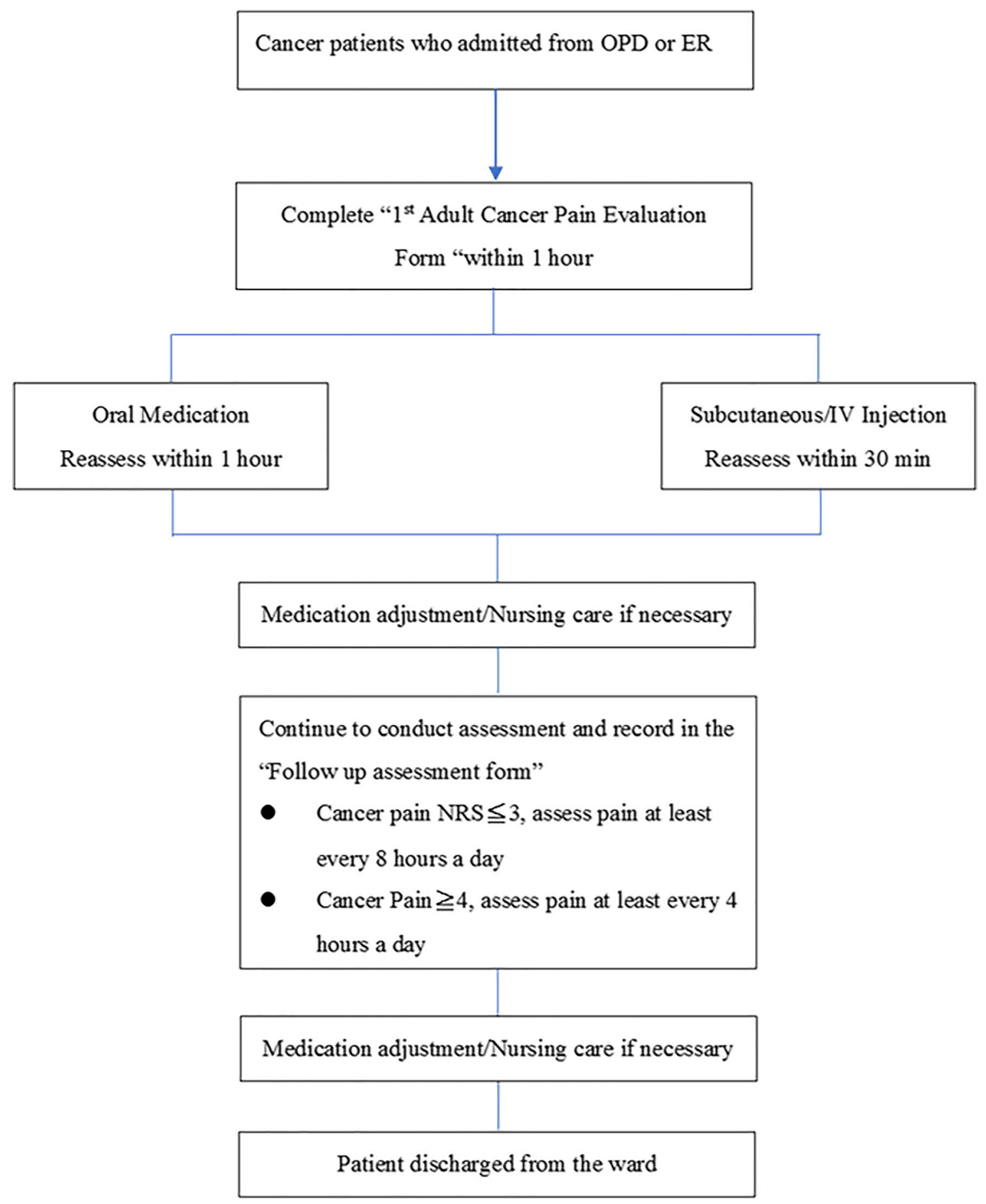

Fig. 1 Good pain management—algorithm 
negative PMI ( $\sim 70 \%$ of Japanese patients and $33 \%$ of Canadian patients). Hence, implementing effective pain management for the current clinical practice has become a crucial target around the world.

Results from several investigations advocate the implementation of a standardized pain management plan. In America, various randomized studies were conducted for the assessment of effects on the education for pain in cancer patients and results showed a decrease in pain intensity following the education [14-16]. Additionally, the Good Pain Management (GPM) ward program implemented in China improved the quality of life (QoL) for patients [17, 18].

Nevertheless, a Taiwanese population-based study revealed that $23.6 \%$ of cancer patients had inadequate pain medication and $47.4 \%$ were not satisfied with the pain relief during admission [19]. Comparable results were observed in another study [20] despite the relevant regulation of pain control launched in 2005 [3]. To standardize pain management in Taiwan, the study aimed to set up the GPM ward with streamlined assessment and management procedures. The program enforced regular pain assessments during the admission, with adequate treatments administered to patients with moderateto-severe cancer pain (i.e., strong-opioids) based on the National Cancer Care Network (NCCN) Adult Cancer Pain Guideline [8]. Patients in this study were recruited based on the good pain management algorithm (Fig. 1)

This study aimed to investigate the benefits and effects of optimal pain control within the first $48 \mathrm{~h}$ after cancer patients with moderate-to-severe cancer pain were hospitalized and planned to demonstrate the viability of the GPM ward in daily practices in Taiwan.

\section{Material and methods}

\section{Study design and procedure}

This randomized, current practice-controlled study was approved by the Institutional Review Board of our Hospital (KMUHIRB-F(II)-20160086) and registered on ClinicalTrials.gov (Identifier: NCT03155516) before enrolling study participants. Adult patients with moderate-to-

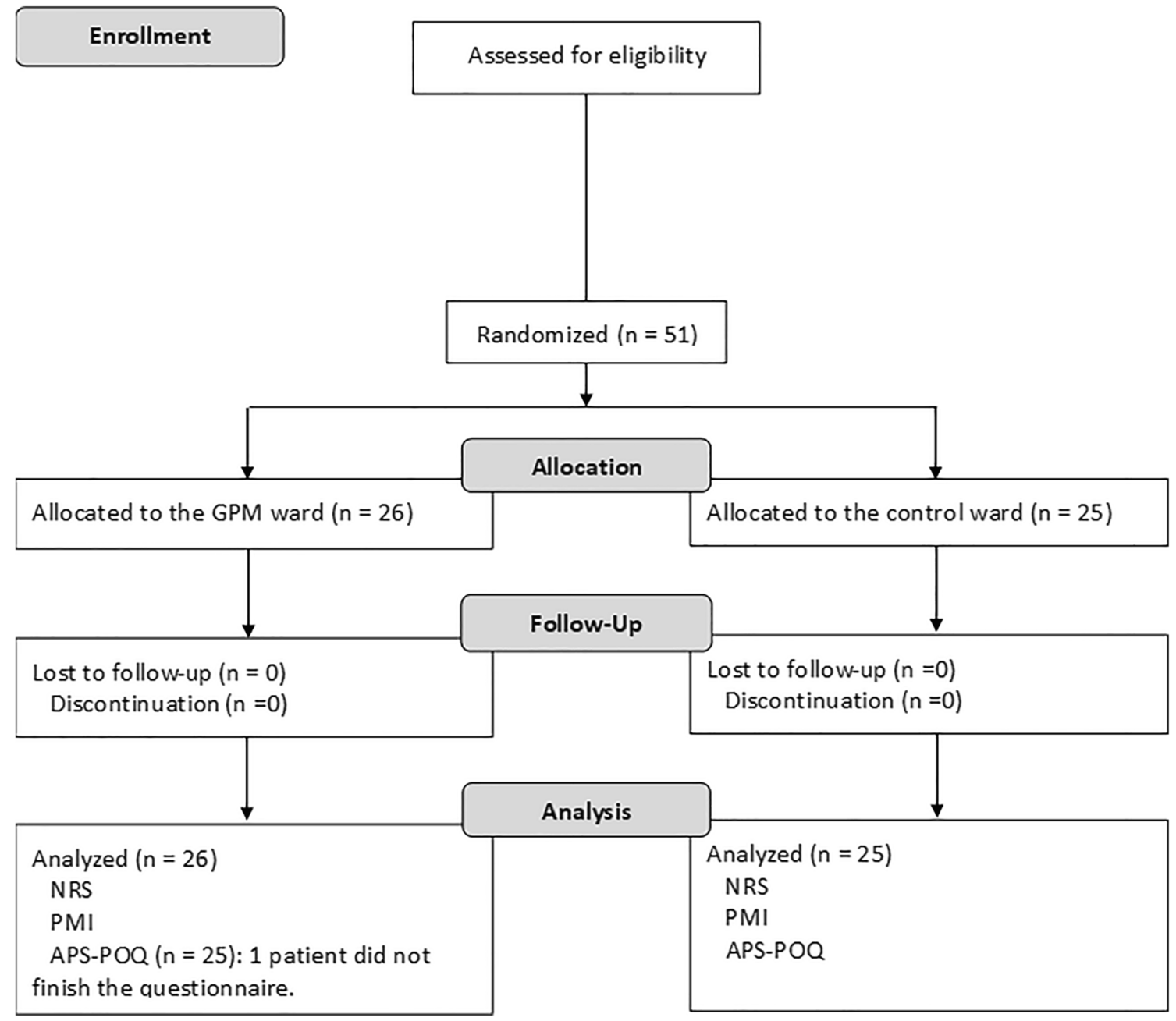

Fig. 2 Flow chart 
severe cancer pain and hospitalized over $24 \mathrm{~h}$ were eligible and randomized into either GPM or control arm in a 1:1 ratio. Patients were excluded if they had non-cancer pain or unexplained pain based on the evaluation of their medical history, moderate-to-severe mental disorder, or received surgery within $24 \mathrm{~h}$ before admission. Data was collected in approximately $48 \mathrm{~h}$ after the entry of this study to evaluate the pain management status of the enrolled patients with moderate-to-severe cancer pain. In the control arm, the pain management for patients was performed under the routine practice with less regular assessments (once every $8 \mathrm{~h}$ ) and reassessments after rescue medication provision. In the GPM arm, patients were evaluated by brief pain inventory (BPI) within $1 \mathrm{~h}$ after admission and treated with analgesics based on a numerical rating scale (NRS) [21, 22]. The pain level was closely monitored using NRS and medication will be adjusted accordingly if the patients' NRS $>4$ and above. Patients with pain intensity of $\leq 3$ points were monitored once at least every $8 \mathrm{~h}$ and those with pain intensity of $\geq 4$ points were monitored at least once every $4 \mathrm{~h}$ until discharge.

\section{Study assessments}

The pain control, adequacy of pain treatments, patients' satisfaction, and QoL were compared between the GPM and control arms. The pain intensity was evaluated using NRS and classified into none (0 points), mild (1-3), moderate (4-6), and severe (7-10). The association between pain intensity and adequacy of analgesics was estimated by PMI [13]. Moreover, the American Pain Society Patient Outcome Questionnaire (APS-POQ) was used to survey the first $24 \mathrm{~h}$ of satisfaction and outcomes after $48 \pm 8 \mathrm{~h}$ of admission.

Ad hoc subgroup analyses based on the pain medication category were also conducted. Two subgroups (strong opioids and non-strong opioids) in both GPM and control arms were divided and parameters such as pain control, patient satisfaction, and QoL were analyzed and compared.

\section{Treatment procedure}

After the randomization, patients in the control arm received treatments following routine practice for pain management,
Table 1 Demographics and pain characteristics of enrolled patients

\begin{tabular}{|c|c|c|c|}
\hline Variables & GPM arm, $n=26$ & Control arm, $n=25$ & $p$ value $^{\mathrm{a}}$ \\
\hline Age (years, mean $\pm \mathrm{SD}$ ) & $52.2 \pm 14.3$ & $56.2 \pm 13.6$ & 0.31 \\
\hline Male, $n(\%)$ & $9(34.6)$ & $9(36.0)$ & $>0.999$ \\
\hline NRS score $($ mean $\pm \mathrm{SD})$ & $6.4 \pm 1.7$ & $5.4 \pm 1.3$ & $0.03 *$ \\
\hline Cancer type & 26 & 25 & \\
\hline Colorectal & 18 & 13 & \\
\hline Gastric & 3 & 3 & \\
\hline Breast & 2 & 3 & \\
\hline Others & 3 & 6 & \\
\hline \multicolumn{4}{|l|}{ Metastasis } \\
\hline No $(\%)$ & $3(11.5 \%)$ & $9(36 \%)$ & \\
\hline Liver & 8 & 5 & \\
\hline Lung & 5 & 4 & \\
\hline Peritoneal & 4 & 3 & \\
\hline Ovary & 3 & 2 & \\
\hline Abdominal wall & 3 & 2 & \\
\hline Lymph node & 2 & 4 & \\
\hline Bowel & 1 & 1 & \\
\hline Bone & 2 & 2 & \\
\hline Presacral & 1 & 0 & \\
\hline Skin & 1 & 1 & \\
\hline \multicolumn{4}{|l|}{ Pain level, $n(\%)$} \\
\hline Moderate & $19(73.1)$ & $20(80.0)$ & 0.56 \\
\hline Severe & $7(26.9)$ & $5(20.0)$ & \\
\hline
\end{tabular}

${ }^{a}$ The difference between groups was analyzed by two-sample $t$ tests for the continuous data and chi-square test or Fisher's exact test for the categorical data

* Significant difference

Abbreviations: GPM, good pain management; $N R S$, numerical rating scale; $S D$, standard deviation 
Fig. 3 A comparison of change in the NRS score between the GPM and control arms. NRS, numerical rating scale; GPM, good pain management; EOT, end of treatment. $* p=0.0013$

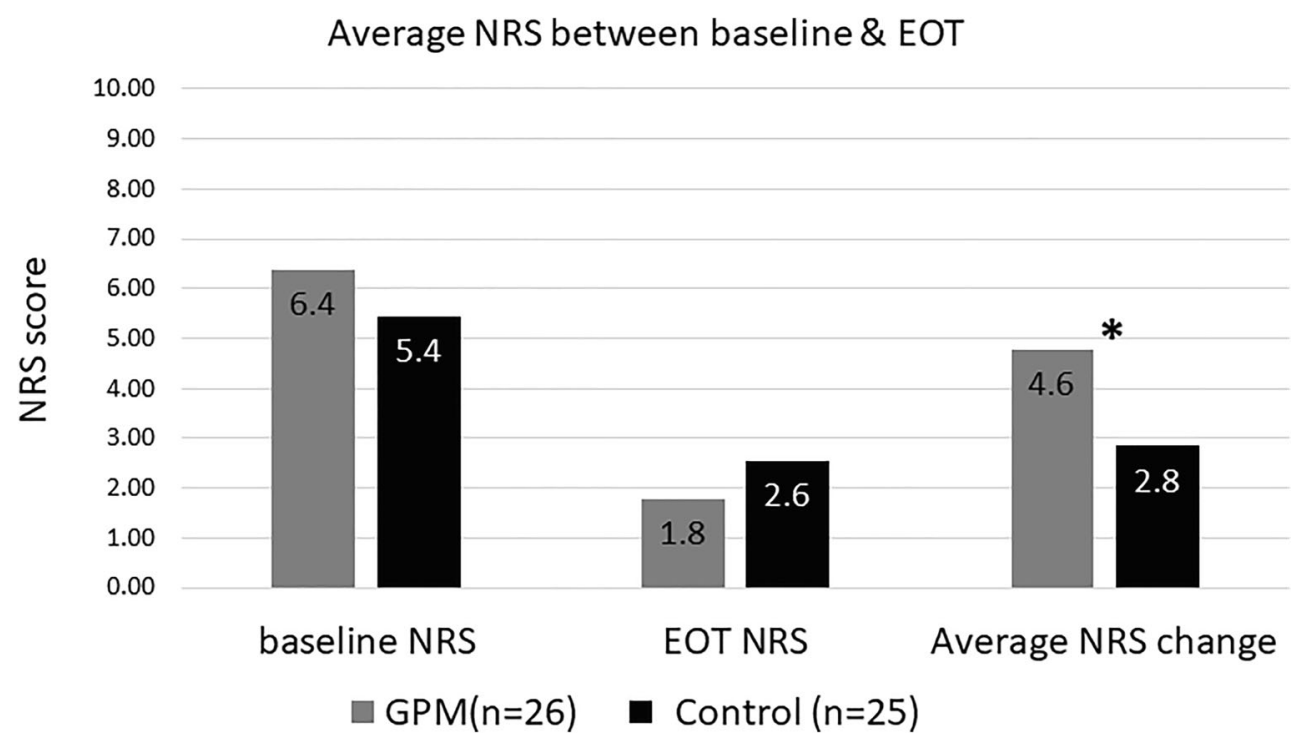

while patients in the GPM arm received analgesics according to pain levels classified by NRS. Non-opioids (e.g., acetaminophen/non-steroidal anti-inflammatory drug, NSAIDs) were given to manage mild pain, and weak/low-dose strong opioids or strong opioids (e.g., morphine, oxycodone, and fentanyl) were given to manage moderate or severe pain. All analgesics were introduced at a tolerable frequency and dosage per physicians' judgments.

\section{Statistical analyses}

Continuous variables were described using the number of observations, mean, median, standard deviation (SD), and 95\% confidence intervals $(95 \% \mathrm{CI})$. Changes from baseline were analyzed by paired $t$ test or Wilcoxon signed rank test based on the normality assumption, and the difference between groups was compared by two-sample $t$ test for normal distribution or the Wilcoxon rank sum test for non-normal distribution. Categorical variables were tabulated as frequency and percentage and compared by the chi-square test or Fisher's exact test as appropriate between groups. The pain reporting outcome was presented as a proportion of different pain intensity among all events. The significant difference was defined by two-sided $p$ value $<0.05$. Data analysis was performed using SAS® statistical software (SAS Institute, Cary, NC, USA) 9.4 .

\section{Results}

\section{Patient demographic}

A total of 51 patients were enrolled from the end of 2016 to August 2017 and randomized to the GPM arm $(n=26)$ or the control arm $(n=25)$ (Fig. 2). Table 1 summarizes the demographics and pain characteristics. Overall, no significant difference was observed between groups and most patients experienced moderate cancer pain. Patients were around 5256 years old and approximately $36 \%$ of them were male. More than $70 \%$ of the patients suffered from cancer metastasis with multiple sites.
Fig. 4 The frequency of pain reported in the GPM and control arms. GPM, good pain management. $* p<0.0001$

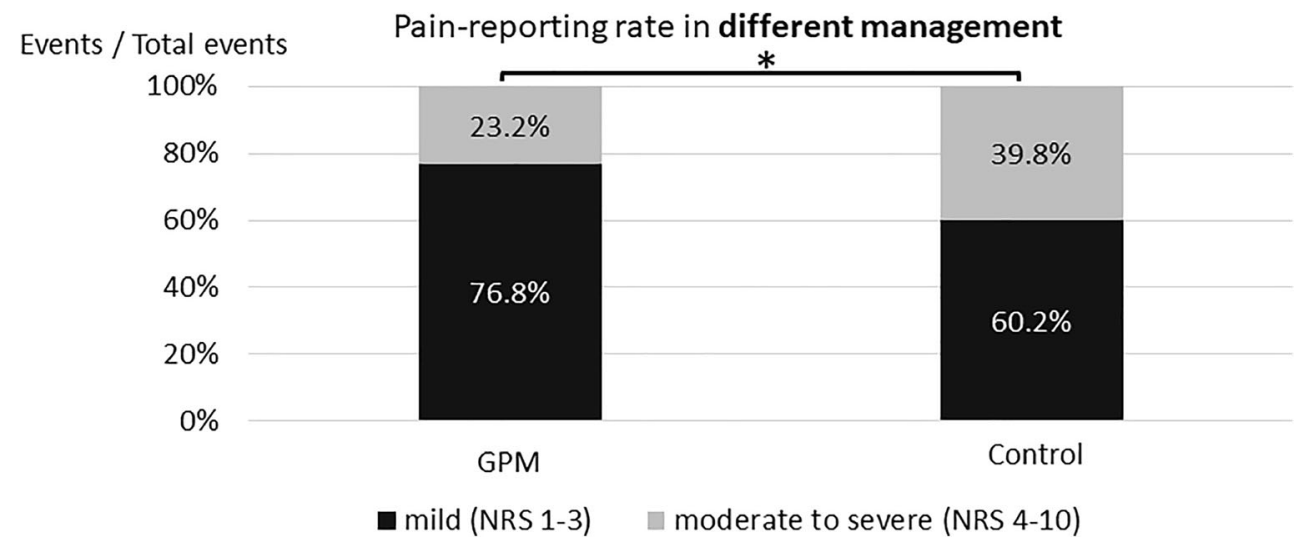


Table 2 Treatment prescribed for 51 cancer patients

Treatment for pain control Pain levels during admission, events (\%)

\begin{tabular}{|c|c|c|c|c|c|c|c|c|c|c|}
\hline & \multicolumn{5}{|c|}{ GPM group } & \multicolumn{5}{|c|}{ Control group } \\
\hline & No pain & Mild & Moderate & Severe & Total & No pain & Mild & Moderate & Severe & Total \\
\hline No treatment & $0(0.0)$ & $0(0.0)$ & $0(0.0)$ & $0(0.0)$ & $0(0.0)$ & $0(0.0)$ & $0(0.0)$ & $2(5.4)$ & $0(0.0)$ & $2(3.9)$ \\
\hline Non-opioid & $0(0.0)$ & $1(14.3)$ & $0(0.0)$ & $0(0.0)$ & $1(1.5)$ & $0(0.0)$ & $0(0.0)$ & $2(5.4)$ & $0(0.0)$ & $2(3.9)$ \\
\hline Weak opioid & $0(0.0)$ & $1(14.3)$ & $16(35.6)$ & $1(7.7)$ & $18(27.3)$ & $0(0.0)$ & $0(0.0)$ & $13(35.1)$ & $1(8.3)$ & $14(27.5)$ \\
\hline Strong opioid & $1(100.0)$ & $5(71.4)$ & $29(64.4)$ & $12(92.3)$ & $47(71.2)$ & $0(0.0)$ & $2(100)$ & $20(54.1)$ & $11(91.7)$ & $33(64.7)$ \\
\hline Total & $1(1.5)$ & 7 (10.6) & $45(68.2)$ & $13(19.7)$ & 66 & $0(0.0)$ & $2(3.9)$ & $37(72.5)$ & $12(23.5)$ & 51 \\
\hline
\end{tabular}

Abbreviation: GPM, good pain management

\section{Pain control}

The mean change from baseline in the NRS score is presented in Fig. 3. After 48-h pain management, the mean change in NRS score was significantly higher for the GPM ward (-4.6) compared with that for the control ward $(-2.8)(p=0.0013)$. The frequency of pain reporting stratified by pain levels is shown in Fig. 4. The percentage of moderate-to-severe pain events in the GPM ward was significantly lower than in the control ward $(23.2 \%$ vs. $39.8 \% ; p<0.0001)$.

\section{Adequacy of pain treatment}

The summary of analgesic administration following different pain management is tabulated in Table 2. For patients with moderate-to-severe pain, the prescription rate for strong opioids was higher in the GPM ward than in the control ward (70.7\% [41/58] vs. $63.3 \%$ [31/49]). The mean PMI score was significantly higher for the GPM ward than for the control ward ( 0.64 vs. $0.33, p=0.0343)$, suggesting that patients in the GPM ward were more likely to receive adequate pain relief.

\section{Effects on patients' quality of life}

Figure 5 illustrates the APS-POQ outcomes regarding patients' satisfaction and QoL. In general, patients' satisfaction and QoL in two arms were comparable (both $p>0.05$ ) and had no significant difference.

\section{Ad hoc analysis based on the pain medication category}

To have a deeper understanding of the results from the study, an ad hoc analysis was conducted. Based on the pain medication that the patients were prescribed, the data of the 2 patient groups (strong opioid group and non-strong opioid group) were divided for further analysis. Thirty-seven patients were identified as a strong opioid group and 14 patients as nonstrong opioid group. The ad hoc analysis of the pain control rate showed no statistical difference between the strong opioid subgroup and non-opioid subgroup in the GPM arm, while there was a significant difference in the higher moderate-tosevere pain reporting rate in the strong opioid subgroup compared with the non-opioid subgroup in the control arm (Fig. 6). This may imply the intervention of GPM will help the patients who need strong opioids to have less moderate-to-severe cancer pain. Similar results were also observed; when comparing the GPM arm with control arm in the strong opioid subgroup, a significant reduction of moderate-to-severe reporting rate in the GPM arm was noted $(21.7 \%$ vs. $45.2 \%, p<0.0001$, data not shown). There was no significant difference in the moderate-to-severe reporting rate between the GPM and
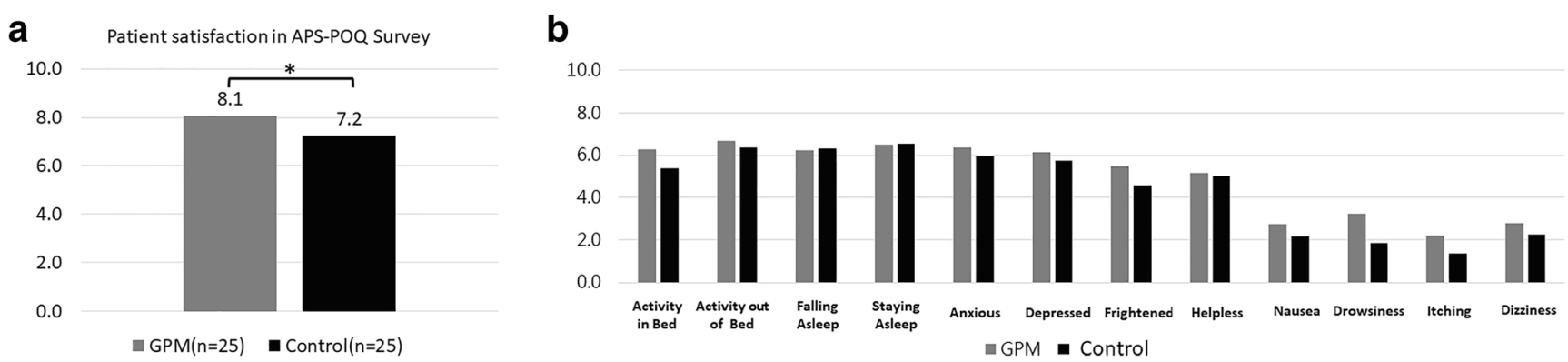

Fig. 5 The difference between the GPM and control arms using APS-POQ. a. Patient satisfaction $* p=0.724$. b Overall outcomes. APS-POQ, American Pain Society Patient Outcome Questionnaire; GPM, good pain management. All $p>0.05$ 
Fig. 6 The frequency of pain reporting in the GPM and control arms - ad hoc subgroup analysis based on the pain medication category (strong opioid group and non-opioid group). $* p=0.4046$; $* * p=0.0132$, chi-square test

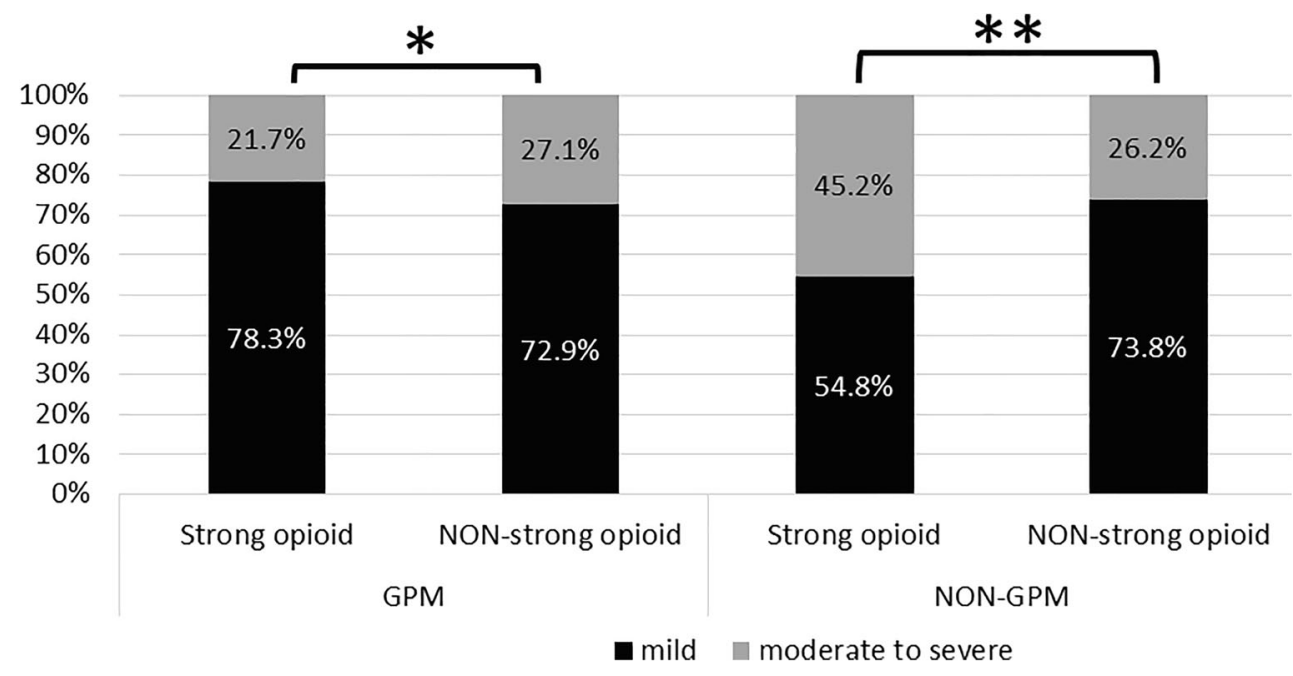

control arms within the non-opioid patient subgroup ( $27.1 \%$ vs. $26.2 \%, p=1.0$, data not shown).

Since there was no significant difference in patient satisfaction between the GPM and control arms, another ad hoc subgroup analysis was also conducted. Significant patient satisfaction was observed in the GPM arm compared with that in the control arm when the patients were in the strong opioid subgroup (8.1 vs. 6.8, $p=0.0329$, Fig. 7). However, no similar effect was observed between the GPM and control arm in the non-opioid patient subgroup ( 8 vs. $8.1, p=0.8697$, Fig. 7 ).

\section{Discussion}

We collected the data regarding cancer pain management from 51 Taiwanese patients with moderate-to-severe pain in this randomized study. The results indicated that the implementation of the GPM program in wards provided better and sooner pain relief than routine practices within the first $48 \mathrm{~h}$ of patients who were admitted to the hospital with moderate-tosevere cancer pain. Compared with the control arm, the
GPM arm showed a significantly greater pain reduction levels in the NRS score and reported fewer numbers of moderate-tosevere pain. Also, a higher PMI score was found in the GPM arm, although the higher number of PMI may not necessarily reflect more adequate pain management. These data suggest that cancer pain can be managed efficiently within $48 \mathrm{~h}$ after being admitted through the GPM approach.

This GPM program has been implemented in China and our results are similar to studies conducted in China in supporting the standardized GPM program to improve pain control [17, 18]. Yang et al. [17] revealed that the mean PMI score for the GPM ward was significantly higher than for the control arm.

However, surprisingly, our PMI results were prominently superior to those in the Chinese study regardless of GPM or control arms (Taiwan vs. China: $0.33-0.64$ vs. -0.261 to 0.0083 ), somehow indicating more adequate cancer pain care management in our hospital system using GPM approaches.

The assessment of the patients is always the very first step for cancer pain management [23]. Compared with other countries regarding standardized pain management, a $\sim 52 \%$
Fig. 7 The ad hoc subgroup analysis of patient satisfaction (APS-POQ). Comparison on patient satisfaction on GPM and control ward among the same patient groups (strong opioid group and non-opioid group, $* p=0.0329 ; * * p=0.8697$, independent two-sample t-test)

\section{Ad hoc Subgroup Analysis of Patient Satisfaction}

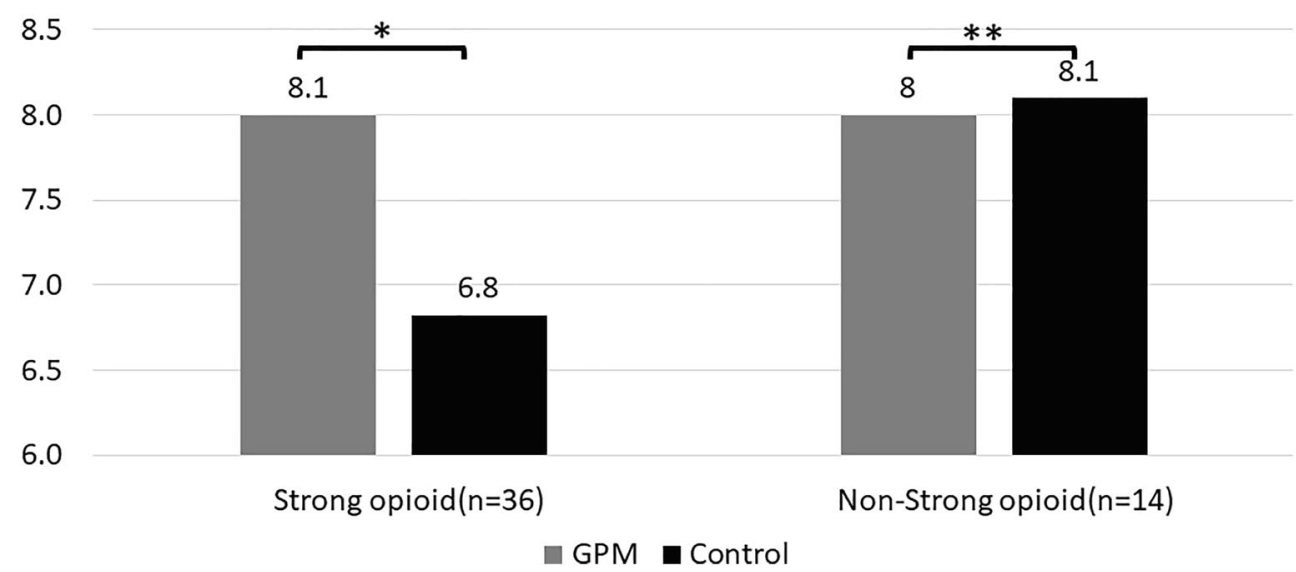


reduction of NRS score in the control arm of our study was comparable with that of other studies. Under the routine care for pain in cancer patients, about $52 \%$ NRS reduction for all pain levels was observed in Thailand [24], and a 59\% decrease in the NRS score was recorded in Germany [25]. Nevertheless, in the GPM arm of our study, it contributed to a higher decrease in the NRS score by $70 \%$.

However, studies in other countries following the WHO guidelines $[23,26]$ to manage the cancer pain showed smaller reductions in pain levels in Italy (48\%) [27], Greece (57\%) [28], Brazil (50-65\%) [29], and Thailand (65\%) [24]. These findings demonstrated the effectiveness of the GPM approach in our hospital system. GPM approach may provide another better, standardized method for cancer pain management in the hospital cancer ward.

With respect to the influence on patients' quality of life, no significant difference in satisfaction/QoL between the two arms was noted. The ad hoc subgroup analysis of patient satisfaction showed significant patient satisfaction observed in the strong opioid patient subgroup of the GPM arm compared with the subgroup in the control arm but no difference in the non-opioid patient group. This may be because the GPM approach can provide more pain assessments on patients who need strong opioids so that healthcare professionals can identify more patients' needs and provide more help to relieve their cancer pain. The ad hoc analysis results were similar to the results from the GPM program in China and showed an improved satisfaction/QoL in the GPM group [30, 31].

In addition, another study conducted by Wang et al. [32] showed comparable satisfaction/QoL at the time of discharge among the GPM and control arms; however, with continuous GPM approach after discharge, satisfaction/QoL outcome was significantly improved in the GPM arm 1 month after discharge, implying that the GPM approach was not only able to improve the cancer pain management in hospital ward but also was very useful when GPM approach is performed in outpatient department and maintain patient's outcome for a longer period of time after discharge.

Our study had some shortcomings. First, the patient number enrolled was relatively small. Second, we only followed up patients for $48 \mathrm{~h}$ for the study purposes and we were not able to see a long-term effect even after discharge from the hospital. Third, previous researches $[2,33]$ pointed out that the validity of PMI applied for measuring the quality of cancer pain management was limited because it merely considered the pain intensity and types of prescribed opioids as the determinants, excluding potential factors such as disease stage, pain characteristics, complementary therapy, and geographical area.

Based on this preliminary study, we may consider different parameters that can demonstrate more details in future studies in Taiwan. Large-scale studies focusing on $48 \mathrm{~h}$ and a longer follow-up period may be necessarily performed to confirm our findings in more detail. Quality-/quantity-related indicators may be identified through those studies so that they will help the HCPs to manage cancer pain in a cost-effective manner.

\section{Conclusion}

This pilot study revealed that the implementation of the GPM ward program is viable in daily practices and effective for the improvement of cancer pain management in Taiwan, especially in the first $48 \mathrm{~h}$ after admission, especially for those patients with moderate-to-severe cancer pain who need strong opioids. The GPM ward program may help to optimize cancer pain management in cancer wards with clear key monitoring indicators in Taiwan.

Acknowledgments The authors thank their co-workers for their participation in this study and the support from Taiwan Mundipharma Pharmaceuticals Ltd.

Author contributions WC Su and $\mathrm{CH}$ Chuang contributed equally to this work. All authors contributed, reviewed, and approved the final manuscript.

Funding information This work was supported by grants through funding from the Ministry of Science and Technology (MOST 1092314-B-037-035, MOST 109-2314-B-037-040, MOST 109-2314-B037-046-MY3) and the Ministry of Health and Welfare (MOHW107TDU-B-212-123006, MOHW107-TDU-B-212-114026B, MOHW108TDU-B-212-133006, MOHW109-TDU-B-212-134026, MOHW109TDU-B-212-114006, MOST109-2314-B-037-040, MOST 109-2314-B037-035) funded by Health and welfare surcharge of tobacco products, and the Kaohsiung Medical University Hospital (KMUH108-8R34, KMUH108-8R35, KMUH108-8M33, KMUH108-8M35, KMUH1088M36, KMUH106-6M30, KMUH105-5M21, KMUH104-4M25, KMUH-DK109005 3) and Center for Cancer Research (KMUTC108A04) and Cohort Research Center Grant (KMU-TC108B07), Kaohsiung Medical University. In addition, this study was supported by the Grant of Taiwan Precision Medicine Initiative, Academia Sinica, Taiwan, R.O.C.

Compliance with ethical standards This randomized, current practice-controlled study was approved by the Institutional Review Board of our Hospital (KMUHIRB-F(II)-20160086).

Conflict of interest The authors declare that they have no conflict of interest.

Open Access This article is licensed under a Creative Commons Attribution 4.0 International License, which permits use, sharing, adaptation, distribution and reproduction in any medium or format, as long as you give appropriate credit to the original author(s) and the source, provide a link to the Creative Commons licence, and indicate if changes were made. The images or other third party material in this article are included in the article's Creative Commons licence, unless indicated otherwise in a credit line to the material. If material is not included in the article's Creative Commons licence and your intended use is not permitted by statutory regulation or exceeds the permitted use, you will need to obtain permission directly from the copyright holder. To view a copy of this licence, visit http://creativecommons.org/licenses/by/4.0/. 


\section{References}

1. van den Beuken-van Everdingen MH, de Rijke JM, Kessels AG, Schouten HC, van Kleef M, Patijn J (2007) Prevalence of pain in patients with cancer: a systematic review of the past 40 years. Ann Oncol 18(9):1437-1449

2. Deandrea S, Montanari M, Moja L, Apolone G (2008) Prevalence of undertreatment in cancer pain. A review of published literature. Ann Oncol 19(12):1985-1991

3. Laws \& Regulations Database of The Republic of China (2014). Regulations for Cancer Care Quality Assurance Measures. Laws \& Regulations Database of The Republic of China. https:/law.moj. gov.tw/ENG/LawClass/LawAll.aspx?pcode=L0070016. Accessed 30 March 2020

4. Serlin RC, Mendoza TR, Nakamura Y, Edwards KR, Cleeland CS (1995) When is cancer pain mild, moderate or severe? Grading pain severity by its interference with function. Pain. 61(2):277-284

5. Laird BJ, Boyd AC, Colvin LA, Fallon MT (2009) Are cancer pain and depression interdependent? A systematic review. Psycho-oncology. 18(5):459-464

6. Lin CC, Lai YL, Ward SE (2003) Effect of cancer pain on performance status, mood states, and level of hope among Taiwanese cancer patients. J Pain Symptom Manag 25(1):29-37

7. WHO (2002) National cancer control programmes : policies and managerial guidelines, 2nd edn. World Health Organization, Geneva

8. NCCN Network® (2020) NCCN Clinical Practice Guideline in Oncology - Adult Cancer Pain (Version 1). NCCN org

9. American Society of Anesthesiologists Task Force on Chronic Pain Management; American Society of Regional Anesthesia and Pain Medicine (2010) Practice guidelines for chronic pain management: an updated report by the American Society of Anesthesiologists Task Force on Chronic Pain Management and the American Society of Regional Anesthesia and Pain Medicine. Anesthesiology 112(4):810-833

10. Ripamonti CI, Santini D, Maranzano E, Berti M, Roila F (2012) Management of cancer pain: ESMO Clinical Practice Guidelines. Ann Oncol 23(Suppl 7):vii139-vii154

11. Okuyama T, Wang XS, Akechi T, Mendoza TR, Hosaka T, Cleeland CS, Uchitomi Y (2004) Adequacy of cancer pain management in a Japanese cancer hospital. Jpn J Clin Oncol 34(1):37-42

12. Vuong S, Pulenzas N, DeAngelis C, Torabi S, Ahrari S, Tsao M, Danjoux C, Barnes T, Chow E (2016) Inadequate pain management in cancer patients attending an outpatient palliative radiotherapy clinic. Support Care Cancer 24(2):887-892

13. Cleeland CS, Gonin R, Hatfield AK, Edmonson JH, Blum RH, Stewart JA, Pandya KJ (1994) Pain and its treatment in outpatients with metastatic cancer. N Engl J Med 330(9):592-596

14. Oldenmenger WH, Sillevis Smitt PA, van Montfort CA, de RaafPJ, van der Rijt CC (2011) A combined pain consultation and pain education program decreases average and current pain and decreases interference in daily life by pain in oncology outpatients: a randomized controlled trial. Pain. 152(11):2632-2639

15. Thomas ML, Elliott JE, Rao SM, Fahey KF, Paul SM, Miaskowski C (2012) A randomized, clinical trial of education or motivationalinterviewing-based coaching compared to usual care to improve cancer pain management. Oncol Nurs Forum 39(1):39-49

16. Kravitz RL, Tancredi DJ, Grennan T, Kalauokalani D, Street RL Jr, Slee CK, Wun T, Oliver JW, Lorig K, Franks P (2011) Cancer health empowerment for living without pain (Ca-HELP): effects of a tailored education and coaching intervention on pain and impairment. Pain. 152(7):1572-1582

17. Yang YP, Ma YX, Huang Y, Zhao YY, Xu F, Tian Y, Zou BY, Gao RZ, Zhang L (2014) The good pain management (GPM) ward program in China and its impact on Chinese cancer patients: the SYSUCC experience. Chin J Cancer 33(7):323-329

18. Yu S-Y, Wang J-J, Huang Y-G, Hu B, Wang K, Li PP, Wu YL, Zhang HL, Zhang L, Zhang QY, Qin SK (2016) Managing pain in patients with cancer: the Chinese good pain management experience. J Glob Oncol 3(5):583-595

19. Tang ST, Tang WR, Liu TW, Lin CP, Chen JS (2010) What really matters in pain management for terminally ill cancer patients in Taiwan. J Palliat Care 26(3):151-158

20. Liang S-Y, Li C-C, Wu S-F, Wang T-J, Tsay S-L (2011) The prevalence and impact of pain among Taiwanese oncology outpatients. Pain Manag Nurs 12(4):197-205

21. van den Beuken-van Everdingen MH, de Rijke JM, Kessels AG, Schouten HC, van Kleef M, Patijn J (2007) High prevalence of pain in patients with cancer in a large population-based study in the Netherlands. Pain. 132(3):312-320

22. Deng D, Fu L, Zhao YX, Wu X, Zhang G, Liang C, Xie CH, Zhou YF (2012) The relationship between cancer pain and quality of life in patients newly admitted to Wuhan Hospice Center of China. Am J Hosp Palliat Care 29(1):53-59

23. WHO (2019) Guidelines for the pharmacological and radiotherapeutic management of cancer pain in adults and adolescents Geneva. World Health Organization, Geneva

24. Subongkot S, Khounnikhom S, Johns NP, Sookprasert A (2008) Exploration the results of cancer pain management following implementation of World Health Organization (WHO) pain guidelines. Isan JPharam Sci 4(1):77-96

25. Meuser T, Pietruck C, Radbruch L, Stute P, Lehmann KA, Grond S (2001) Symptoms during cancer pain treatment following WHOguidelines: a longitudinal follow-up study of symptom prevalence, severity and etiology. Pain. 93(3):247-257

26. World Health Organization (1996) Cancer pain relief : with a guide to opioid availability, 2nd ed. World Health Organization. https:// apps.who.int/iris/handle/10665/37896. Accessed 30 March 2020

27. Marinangeli F, Ciccozzi A, Leonardis M, Aloisio L, Mazzei A, Paladini A, Porzio G, Marchetti P, Varrassi G (2004) Use of strong opioids in advanced cancer pain: a randomized trial. J Pain Symptom Manag 27(5):409-416

28. Mystakidou K, Parpa E, Tsilika E, Katsouda E, Kouloulias V, Kouvaris J, Georgaki S, Vlahos L (2004) Pain management of cancer patients with transdermal fentanyl: a study of 1828 step I, II, \& III transfers. J Pain 5(2):119-132

29. Nunes BC, Garcia JB, Sakata RK (2014) Morphine as first medication for treatment of cancer pain. Braz J Anesthesiol 64(4):236240

30. Qiu RZJ, Zhang L et al (2014) An evaluation of the role and effectiveness of pain management in cancer pain GPM ward [in Chinese]. J Nurse Training 29:994-996

31. Yang FLS, Ren H (2014) Application of the 'systematic approach to holistic nursing care' in cancer pain GPM demonstration wards [in Chinese]. J Basic Clin Oncol 27:162-165

32. Wang B, He Kun, Wang J, The Second Affiliated Hospital to Xi' an Jiaotong University (2014) Application of PDCA combined with $\mathrm{PlO}$ health education model on the follow-up of patients with standardised treatment of cancer pain in the service demonstration ward [in Chinese]. J Qilu Nursing 21:13-15

33. Greco MT, Roberto A, Corli O, Deandrea S, Bandieri E, Cavuto S, Apolone G (2014) Quality of cancer pain management: an update of a systematic review of undertreatment of patients with cancer. J Clin Oncol 32(36):4149-4154

Publisher's note Springer Nature remains neutral with regard to jurisdictional claims in published maps and institutional affiliations. 